\title{
Climate change is real: fungal perspective!
}

\author{
Apekcha Bajpai*1 and Bhavdish N. Johri ${ }^{2}$ \\ ${ }^{\prime}$ Department of Microbiology, Barkatullah University, Bhopal 462026 (M.P.), India \\ ${ }^{2}$ Department of Biotechnology, Barkatullah University, Bhopal 462026 (M.P.), India \\ *Corresponding author email: apekshabajpai@gmail.com
}

(Submitted on September 2,2019; Accepted on November 5,2019)

\section{ABSTRACT}

\begin{abstract}
Climate change is apparent around the globe as it is dramatically affecting the natural ecosystems. The preliminary cause of climate change is increased green house gases, deforestation, and anthropogenic activities and the resultant change is seen in the form of extreme events like increased temperature, rainfall, permafrost thaw, glacial retreats, sea level, greater occurrence of wildfires, etc (NASA, 2016). It is causing tremendous effect on biodiversity therefore it becomes a serious concern globally. At the face of climate change the macroscopic organisms are either extinct or are at the verge of extinction and may adapt themselves for survival; efforts are successfully laid to conserve them but also it is equally important to focus on the existence, adaptation and alterations taking place in community composition of microscopic world. Impact of 1 trillion microbes inhabiting the planet earth on climate can be huge as they can accelerate climate change, exacerbated by pollution and habitat loss. However, they are understudied on climatic front, especially fungi, which represents a major portion of eukaryotic kingdom, resides in diverse habitats, constitutes considerable biomass on planet earth and regulate soil carbon feedback loop by deriving biogeochemical cycles; therefore they could be vulnerable to climate change largely by habitat loss. This review is an effort to draw the attention towards how fungal diversity responds to climate selection pressure either by adaptation or shifts in community composition observed during weather extremes.
\end{abstract}

KEYWORDS: Fungi, climate change, adaptation, green house gas, temperature

\section{GLOBAL CLIMATE CHANGE}

1.1. Climate change: Magnitude: Climate change is a rather slow and degrading process which is not homogeneous and its repercussions will be observed by mankind in the coming years. As Ram Ramanathan, the first person to predict global warming, rightly prefers the term 'climate disruption' over 'climate change' as it accurately points to the severity associated with it (Madden and Ramanathan, 1980). National agencies like NASA (National aeronautics and space administration) and NOAA (National oceanic and atmospheric administration) clearly forecast the magnitude at which climate is changing indicating ocean acidification that is increasing 2 billion tons per year, ocean warming which is more than $0.4{ }^{\circ} \mathrm{F}$ since 1969 to record levels, ocean acidification, glacial retreat, shrinking ice sheets, frequent wildfires and declining sea ice (https://climate.nasa.gov/ evidence/). The global surface temperature in the year 2018 was the highest and was the fourth consecutive warmest year since 1880 and there is no wonder now the year 2019 embarks on a new history. Observing this rapid change of desertification around the world, Sudan is now declared uninhabitable and as one of the most vulnerable countries in the world to climate change (www.climatelinks.org).

Climate change is partly blamed in frequent devastations like wildfires of Colorado, drought occurring in Sudan and hurricane Maria hitting Puerto Rico in 2017 which makes the subject 'climate change' a pressing concern. What are the effects of climate change? Is it just the rise in temperature, water table, atmospheric carbon dioxide and ozone depletion causing a fast decline of macroscopic world or is it also adversely affecting the unseen majority of microscopic world. Climate change confers its deleterious effects equally to all five kingdoms of life, however, the microbes draw lesser attention at the face of climate change and are understudied in the context of conservation strategies. There have been lesser known facts available about their consequence on the belowground diversity and a connection is poorly established as to how do they retaliate towards nature. In this review we will discuss this undermined area of belowground diversity in climate changed scenario with a special focus on fungi and how these microscopic organisms retaliate towards climate change in the macroscopic world.

1.2. Climate change: Prediction: According to IPCC (International Panel on Climate Change) 2013, global warming effects are heterogeneous like alpine, boreal and arctic areas are expected to experience four times greater warming and more variable precipitation than equatorial and temperate regions predicted to increase by $2{ }^{\circ} \mathrm{C}$ whereas EPA (Environmental Protection Agency), 2016 predicts the global mean temperature to increase by at least $2.7^{\circ} \mathrm{F}$ within the next century. Carbon dioxide level tends to surpass $550 \mathrm{ppm}$ in the next 30-80 years which will have detrimental effect on the nutritional value of food crops (Smith and Myers, 2018), likely range of global temperature increase is $2.04 .9^{\circ} \mathrm{C}$, with median $3.2{ }^{\circ} \mathrm{C}$ and a $5 \%$ chance that it will be less than $2{ }^{\circ} \mathrm{C}$ $\left(1.5^{\circ} \mathrm{C}\right)$ by 2100 (Raftery et al., 2017).

1.3. Climate change: a serious concern: Worldwide protests against climate change are taking place and a group like Extinction rebellion declare them as 'unprecedented global emergency' that the humanity is facing at present; highlighting the importance of subject to policy makers (https://rebellion.earth/wp-content/uploads/2019/04/ REBEL-STARTER-PACK-14-March-2019.pdf). Climate change becomes a serious concern when its impact is observed in all kingdoms of life and anthropogenic activities are largely responsible for it. According to IPCC anthropogenic activities have a measurable effect on the climate change for instance, global tourism alone accounts for about $8 \%$ of global green house emission (Lenzen et al., 2018). However, land ecosystem absorbs $30 \%$ of human carbon dioxide emissions otherwise climate change would have been more rapid than it is thought to be. Recently in Australia, Bramble Cay melomys has been officially declared extinct by IUCN in February, 2019 and the reason behind the 
first documented extinction of a mammal species involves climate change due to 'anthropogenic activities' (Woinarski and Burbidge, 2016). Such events are also intensifying the rapid outbreaks of fungal disease and their dispersal and thus threatening the earth's biodiversity. A striking example of detrimental rise in chytrid fungus Batrachochytrium dendrobatidis has led to an extinction of more than $200 \mathrm{sp}$. of frogs; their transmission is largely facilitated by humans (Scheele et al., 2019) and rapid spread of Candida auris in more than 30 countries is alarming (Casadevall et al., 2019). The devastating effect is often measured by the lives lost, effect on marine life includes ocean acidification, effect on wildlife, extinction risk associated with climate change but surprisingly effect on microbial world is seldom discussed.

Are only macrobes at risk of extinction? No, microscopic organisms too are vulnerable to climatic changes that may lead them to extinction, therefore worthy of conservation. Microbes are always assumed to be everywhere but few are particularly found only in specific habitats. For e.g. an anaerobic fungus inhabits in hindgut of the critically endangered Somali wild ass and is now at extinction risk through habitat loss even before it has been formally described. In addition, their interdependence on each other for survival may cause extinction risk to host species (Liggenstoffer et al. 2010). Microbes are often not a separate entity but are an integral part of food webs so that the extinction of one species puts the next species in taxon inadvertently to higher risk. In 2019, Hawaii forests faced the extinction of a rare species of tree snail (Achatinella apexfulva) which is linked to phyllosphere fungi. While feeding on fallen leaves they reduce fungal abundance which protect the tree $\left(O h i^{\prime} a\right)$ from fungal diseases caused by Ceratocystis. Extinction of fungi will not only reduce a member from their kingdom but also affect other species linked to it. Many organisms are dependent on fungi for their nutrition and are species-specific in selecting them as their source of nutrition for e.g., Collembula population is strongly determined by elevated temperature when grazing on fungal species, Resinicium bicolor and Phallus impudicus (A'Bear et al., 2012). Such findings should be given critical importance and are worthy of providing proper conservation strategies, attention and protection since fungi are dominant decomposers and beneficial in several other ways for the ecosystem.

\section{FUNGALDIVERSITY}

Fungi in nature exist as major driver of key biogeochemical cycles involved in the process of decomposition and thus contribute $1.7 \times 10^{27} \mathrm{Mb}$ of DNA (Landenmark et al., 2015) and $12 \mathrm{Gt}$ of carbon biomass is reported to be encompassed by fungi on the planet earth (Bar-On et al., 2018). For example fungi significantly contribute towards about $50-70 \%$ of carbon stored in boreal forest of Scandinavia so that this major portion accounts for the emission and regulation of carbon dioxide from soils (Clemmensen et al., 2013). Moreover, shift in the fungal community structure due to climate change that may favour fungi over other microbes shall have dramatic impact on emission or sequestration of carbon dioxide and accelerating the climate change (Treseder et al., 2016). Microcosm experiment reveals that AMF (Arbuscular Mycorrhizal Fungi) can affect soil and plant stoichiometry under global change of warming and nitrogen pollution; can reduce phosphorus limitation caused by nitrogen input and slow down negative influence of global change on plant growth (Mei et al., 2019).

Fungi belong to the largest eukaryotic kingdom encompassing millions of species containing approximately $1,44,000$ species which are formally named to date (https://stateoftheworldsfungi.org/2018/reports/SOTWFung i_2018_Full_Report.pdf). As is evident from various studies, fungi are inevitably present everywhere and attempts to enumerate their numbers and taxonomic diversity abound in literature (Bajpai et al., 2019). An early attempt by Hawksworth (1991) estimated fungal diversity conservatively at 1.5 million species; subsequently 1.5 million was considered as a working hypothesis (Hawksworth, 2001). Further studies have suggested an altered ratio estimating fungal forms to 3.5 to 5.1 million species (O'Brien, 2005; Blackwell, 2011). Some of these uncertainties are a result of hidden fungal forms in plant world which is largely influenced by geographical location and edaphic factors. Tedersoo et al. (2014) conducted a study of 365 sampling sites globally and stated that the fungal diversity is overestimated by 1.5 to 2.5 times. Therefore, this varying ratio has led Hawksworth and Lücking (2017) to revisit the actual diversity of fungi to be within the range of 2.2 to 3.8 million species. Key drivers involved in controlling the fungal diversity act either directly or indirectly to exert their influence. Direct factors include environmental factors such as temperature and soil moisture. However, former has a positive effect at global and local scale whereas latter has a positive effect at local scale (Allison and Treseder, 2011). Indirect influences include aboveground community of plants which are linked through mycorrhizal interaction, utilize root exudates and are chiefly involved in decomposition process of plant litter. Therefore plant in many ways determines the belowground fungal communities.

\section{SHIFTS IN FUNGAL COMMUNITY}

Here we exemplify climate change, taking examples of few major ecosystems that are rich in microbes and are considered to be the largest in terms of sequestering carbon from atmosphere. As change in the below ground diversity may impact the future climate change therefore, shifts in such communities of micro-organism become important parameter to predict the climate change.

3.1. Soil ecosystem: Nearly $90 \%$ of plants on terrestrial ecosystem are associated with mycorrhizal fungi that helps them acquire nitrogen from soil and thereby improves plant performance. Ectomycorrhiza is a group of fungi that helps plant grow efficiently under high carbon dioxide levels (Terrer et al., 2016) often termed as 'carbon dioxide fertilization effect'. Plants need nitrogen to respond to high levels of carbon dioxide in the atmosphere and therefore they need a readily available source of nitrogen. Weber et al. (2011) studied six different terrestrial ecosystem subjected to elevated carbon dioxide concentration having around $70 \%$ unique species to a given site. High fungal abundance was 
observed in Creosate, Aspen and Marsh whereas Loblolly and scrub supported low fungal abundance. Abundance of Polysporales, Basidiomycota, Pleosporales and Ascomycota in carbon dioxide elevated conditions was obvious whereas Amanita manicota and Chaetomium thermphilium decreased in abundance.

Soil ecosystems are frequently flooded with nitrogenous fertilizer which may inadvertently affect the mycorrhizal communities found in association with the plants. A comprehensive study conducted on 3,000 plots with tens of thousands of trees across United States forest affected with nitrogen pollution was studied; plants showed symbiotic relationship with either ectomycorrhizal fungi which grow on surface or arbuscular mycorrhizal fungi which penetrate deep inside the roots. Lower abundance of ectomycorrhizal fungi in forests with high nitrogen pollution than trees having arbuscular mycorrhiza as their symbiotic partner was their major observation. This implies that nitrogen pollution caused by burning fossil fuels and excess usage of nitrogen based fertilizers on farms makes ectomycorrhizal fungi less abundant in forest (Averill et al., 2018). Losing these fungal groups can increase decomposition and amount of carbon locked in soil and trees which can expedite the climate change process. Even if we keep climate change aside, several antibiotics are extracted from soil fungi and mushrooms that are ectomycorrhizal in nature and loss of ECM from forest means loss of such biologically important compounds from nature. Very few studies focus on these minor changes in nature that can ripple through the ecosystem and eventually they might change the functioning of that particular ecosystem. Interestingly a recent research by Bastin et al. (2019) proposes in their findings that planting trees in 350 million hectares could potentially reduce $26 \mathrm{Gt}$ of atmospheric $\mathrm{CO}_{2}$ that could prove beneficial in mitigating climate change.

Boreal peatlands cover approximately $17 \%$ of boreal zone and represent one of the largest storage of terrestrial carbon. Asemaninejad et al. (2018) assessed the effect of climate change on fungal communities and observed that the frequency of members of Leotiomycetes was similar; however, Sordariomycetes and Eurotiomycetes increased after treatment. Agaricomycetes, Chytridiomycota, Monoblepharidomycetes and Microbotryomycetes increased with time and were a dominant group whereas an opposite trend was observed for Zygomycota. An interesting result of this study was that temperature, water content and organic content influenced fungal communities which in turn altered carbon dynamics of soil. Reasonable explanation given by the author is that during the early stage effect on water table was much pronounced as decomposers were more prominent while elevated temperatures altered the cell membrane composition. Genus Mycena and Tricholoma emerged as a dominant taxa at higher temperature; they are potential cellulose and lignocelluloses decomposer. Increase in Ascomycota group could be an important indication towards the establishment of vascular plants under high temperature in future.

Mucha et al. (2018) hypothesized that strong effects of global warming prevail at biome boundary and northern latitudes. Lactarius, Laccaria, Tomentella, Russula, Hebeloma and Tuber are the most common ectomycorrhizal (ECM) taxa observed in boreal forest and Laccaria, Russula, Clavulina, Tuber and Tomentella responded at elevated temperature. Lactarius and Russula decreased in abundance whereas Wilcoxina and Laccaria increased at higher temperature while Clavulina was significantly more abundant in warmer temperature treatment. Therefore it might be predicted that the future climate change may favour more thermophilic and drought resistant micro-organisms.

A comparative study, for the first time, showed the long term effect of warming on the ECM fungal community in dry and moist tussock tundra region. Cortinarius is prevalent in the moist tundra region and Tomentella was found highly diverse in dry tundra region. Here was a significant decrease in the ECM fungi due to warming, however author suggests certain species are favoured by warming, while certain species go locally extinct due to direct and indirect effect of warming. There is a clear compositional shift in the fungal communities that might affect biogeochemical cycles and soil carbon sequestration (Morgado et al., 2015). In an impressive study by Egidi et al. (2019), 235 soils collected globally from terrestrial ecosystems were analyzed for fungal dominance wherein Ascomycota was found to be dominant member all over the earth especially in tropical and temperate forests. The members of Pezizomycotina, Leotiomycetes, Eurotiomycetes and Dothideomycetes, Tremellomycetes and Mucoromycotina were ubiquitous in distribution. The dominance appeared to be linked to their higher stress tolerance and resource uptake, competitive capabilities like melanin deposition, as well as resistance to antibiotics and secretion of broad array of antibiotics. From the climate perspective this might be the group which is vulnerable as it exhibits habitat preference.

3.2. Marine ecosystem: A reasonable definition given by Pang et al. (2016) for marine fungus is "any fungus that is recovered repeatedly from marine habitats and: 1) is able to grow and/or sporulate (on substrata) in marine environments; 2) forms symbiotic relationships with other marine organisms; or 3) is shown to adapt and evolve at the genetic level or be metabolically active in marine environments."

Nearly $70 \%$ part of planet earth is hydrosphere and dominated mainly by phototrophs and chemotrophs and together with other microbes constitute a population of around $10^{29}$ (Flemming and Wuertz, 2019); fungal counts are around 10,000 species (Jones, 2011). Like terrestrial ecosystems, dominant fungal phyla include Ascomycota and Basidiomycota (Kohlmeyer and Kohlmeyer, 1979) including a high number of novel Chytridiomycota (Comeau et al., 2016) which are closely related to terrestrial fungal species indicates a transitional switch to marine life (Schoch et al., 2009). Marine ecosystems are important to study during climate change because marine phytoplanktons alone can fix $\sim 50 \mathrm{Pg} \mathrm{C}$ per year and have faster turnover rates as compared to terrestrial plants (Behrenfeld, 2014), however turnover rates for marine fungi are yet unknown (Amend et al., 2019). Mainly temperature, availability of nutrients and sunlight control the assembly of microbial community (Sunagawa et 
al., 2015). Besides these three primary factors, water density, stratification, circulation, particulate organic matter, salinity fluctuations and organic or inorganic inputs by various water bodies in the ocean are also key deterministic factors (Amend et al., 2019). Additionally marine environments are also influenced by changing climate that includes water acidification, shifts towards warmer temperature and anthropogenic pollution that indirectly puts marine life to threat. These factors regulate carbon and nitrogen biogeochemical cycles and thereby maintaining a balance between the nutrient input into the atmosphere, hence controlling the climate change (Hurd etal., 2018).

That complex food webs are regulated by fungi in the marine environments has been well exemplified in the studies using DNA stable isotope probing DNA SIP with ${ }^{13} \mathrm{C}$ labeled diatom derived polysaccharide; Cladosporium directly assimilated phytoplankton derived organic matter (Cunliffe et al., 2017). This clearly shows how one domain of life is dependent on the other for nutrition and survival. Therefore, slight perturbations in environmental conditions can shift food webs, primary productivity and carbon release from the oceans (Hutchins and Fu, 2017). Holding et al. (2015) have predicted that rising carbon dioxide levels in the atmosphere and in presence of surplus availability of nutrients in oceans can increase phytoplankton primary productivity. Also, global sea ice index has declined in past few years consequence of which light can penetrate deep into the oceans that will eventually increase the primary productivity (Kirchman et al., 2009). However, Behrenfeld et al. (2017) predicted different patterns for productivity in polar regions and this somehow points the need for long term data in community composition. Marine ecosystems also face anthropogenic pollution in forms of plastic and limited studies point towards the capability of fungi to degrade them. Aspergillus tubingensis, a soil fungus (Khan et al., 2017) and Zalerion maritimum, a marine fungus (Paco et al., 2017) have the potential to degrade polyurethane and polyethylene to lessen down anthropogenic pollution such as plastic pollution, respectively.

Fungi also interact with other organisms and show mutualistic relationships that influence the overall health of the host. One such example is coral reefs, they are major sites vulnerable to climate change and fungi being the partner of the holobiont becomes an important area to study. Corals are strongly influenced by range of microbes in association (Torda et al., 2017) and ocean acidification causes species specific difference in sensitivities towards changing environment (Comeau et al., 2019). Perturbations in environmental cause decline in corals and possibly a shift in the ecosystem towards microalgae that is something certain to happen(Enochs et al., 2015).

\section{CARBON SEQUESTRATION}

The amount of carbon dioxide released into the atmosphere as a result of decomposition of soil organic matter is called carbon footprint and this carbon dioxide emission has the potential to severe the climate change effects. Every act of decomposition process leaves a carbon footprint including microbes. The total carbon on the earth is balanced by the carbon cycle derived by mainly fungi and bacteria which either act as generator or user of these gases in the cycle. As it is a proven fact that soil respiration increases with rise in temperature therefore the global warming is actually accelerating the metabolic processes of microbes and fluxing more green house gases rapidly into the atmosphere. Then the question arises how much do soil microbes contribute to atmospheric carbon dioxide? Indices such as carbon utilization efficiency (CUE) is the ratio of microbial biomass carbon to microbial biomass plus carbon dioxide, used to determine the efficiency of organic matter conversion to microbial products relative to carbon dioxide released via respiration (Sinsabaugh et al., 2013). Global assessment of ecosystem carbon turnover time is found to be 23 years and carbon resides in soils near equator for a shorter time than at latitudes $75^{\circ}$ North (Carvalhais et al., 2014) indicating a clear dependence of turnover on temperature and precipitation. From the recent data the microbial contribution in release of carbon from the soil increased by $1.2 \%$ since 1900 , surpassing plants' conversion of carbon dioxide to oxygen (Bailey et al., 2018). Therefore, it is imperative to utilize those microbes that extract carbon dioxide from atmosphere and store it in soils (Fig. 1). Prof David Johnson of New Mexico State University vehemently recommended utilization of microbes with high fungal to bacterial ratio strongly towards fungi (unpublished data). His findings support the fact that increased ratio towards fungi effectively utilizes nutrients from soil and reduces the emission of carbon dioxide to the atmosphere (Berger, 2019).

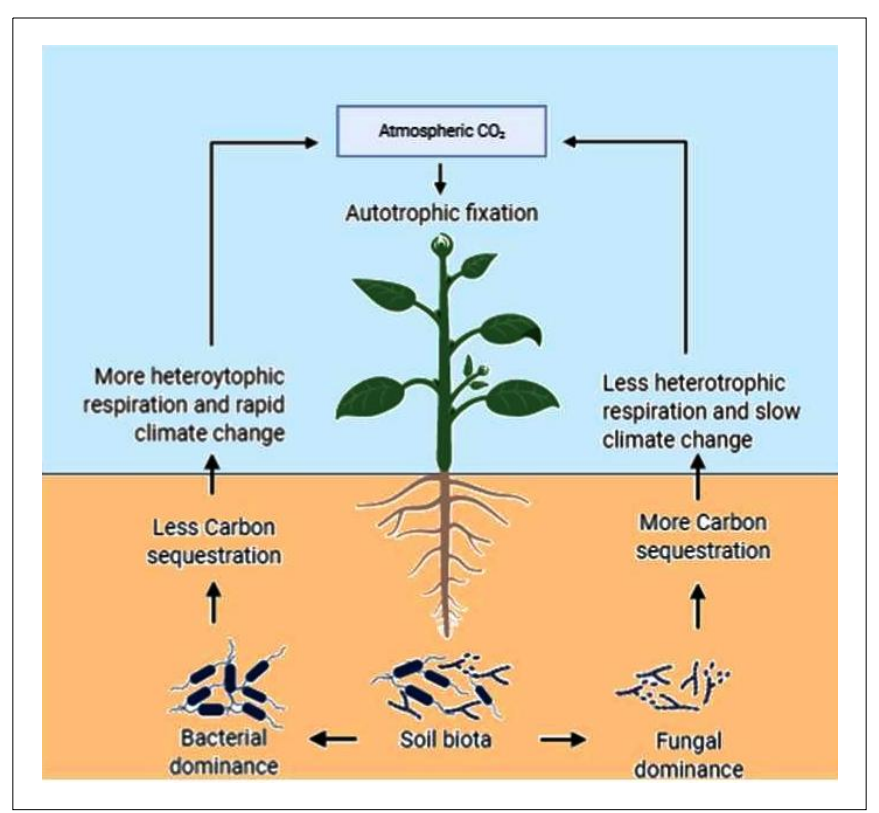

Fig. 1. Management of soil microbial communities to enhance carbon sequestration. Fungi are more efficient than bacteria in terms of abundance, high metabolic rate and are key determinant in deriving major biogeochemical cycles. They utilize root exudates released from plants fixed by photosynthesis for nutrition and lock them in soil as organic carbon and a fraction of which is released as $\mathrm{CO}_{2}, \mathrm{CH}_{4}$ through the process of heterotrophic respiration and methanogenesis, respectively. Keeping a high fungal to bacterial ratio in soil can help to lock more carbon in soil, slow down $\mathrm{CO}_{2}$ release and most likely to mitigate climate change. 


\section{FUNGI-SOIL-ATMOSPHERE CONTINUUM!}

Climate has direct as well as indirect effects on fungal communities. Direct effect includes temperature and water that can affect fungi. Temperature rise can increase the abundance and activity of fungal species directly as they are favoured in warm climate. While the location lowered down the water table can compel fungi for adapting survival strategy using hyphae for long distance transport for water. On the other hand, indirect factors include plant communities that influence fungal partners residing as mutualists through photosynthetic exudates of roots (Treseder et al., 2016).

5.1. Temperature: An interconnection exists between atmosphere and soil biodiversity compartments and for the first time an underground network of microbes that connects plant diversity has been mapped. A global survey extended in around 70 countries, gave a term 'wood wide web' to denote how the symbiotic association of fungi with plants alters with latitude. Warm and tropical forests near equator where decomposition is rapid are dominated by AMF whereas boreal forests near poles where decomposition is slow are predominantly occupied by ECM. What unique this study brings out is the remarkable difference in the diversity of AMF and ECM that changes with the change in the local climate forming transitional zones along the latitudes. This led authors to predict that as the earth warms, there is apparent shift of about $10 \%$ of EM associated trees to AM associated trees (Steidinger et al., 2019). Staddon et al. (2002) have demonstrated an indirect effect on mycorrhizal communities due to temperature induced changes in plant communities. Any change in plant community due to climate change is reflected in the mycorrhizal communities. However, in contrast to this Newsham and colleagues (2016) using a pyrosequencing approach observed a direct relationship between the rising temperature and fungal diversity with an increase of 11.3 fungal taxa per degree Celsius rise in surface temperature. Warmer habitats favour higher diversity of fungi especially genus Verrucaria and among yeast Rhodotorula and Helotiales, Cladosporium and some unclassified OTU of ascomycete decrease in warmer regions. They deduced that there could be a rise of up to $27 \%$ in the diversity of fungi in Antarctic soils by 2100 . There will be a significant increase in the nutrient decomposition hence more biological productivity. However, loss of trees in Amazonia can also result into loss of their symbiotic partners and as the long term 50 years record suggests these trees are fast declining due to elevated temperatures (Gloor, 2019). Replenishing the ecosystem with natural forests (Lewis et al., 2019) and non native trees can improve the carbon sequestration from the atmosphere (Woodcock et al., 2017).

5.2. Green house gases: The earth is surrounded by thick layer of gases and they trap heat from the atmosphere making the planet warmer than before. Such gases are termed as green house gases and those having predominant role in global warming are carbon dioxide, methane and nitrous oxide.

In a long term study of 26 years to deduce the soil and temperature relation it was observed that the world currently emits from fossil fuel burning about 10 billion metric tons of carbon into the atmosphere in the form of carbon dioxide (Melillo et al., 2017). The authors expect the situation to be more severe as at present soil organic matter in Arctic is locked in the ice but according to findings of Lee et al. (2017) arctic ice has started melting at a faster pace creating ice-free area and so the flux of carbon dioxide into the atmosphere produced upon decomposition of soil organic matter has risen. The severity of the matter could be well related from a recent study that reports that breakage of fast ice in Antarctica has led to disappearance of emperor penguin colony from Halley Bay site; scientists call it as a 'catastrophic breeding failure' since sea ice condition is a result of climate change (Fretwell and Trathan, 2019). Fungi are involved in storing carbon in soil, and soil with ECM can store $70 \%$ more carbon than soil without ECM. Therefore, one can argue that the amount of carbon stored and the rate at which it converts to atmospheric carbon dioxide is determined by ECM members. Staddon et al. (2002) demonstrated that elevated carbon dioxide only effects the plant growth and not the mycorrhizal partners of plants. A contrasting study by Tedersoo et al. (2014) states that climate change may potentially reduce ECM fungi thus expediting the process in the future. A study by Kohler et al. (2009) demonstrates the effect of carbon dioxide on fungal diversity in arid and semi arid Mediterranean regions. A negative trend of mycorrhizal colonization was observed with elevated carbon dioxide (760 ppm) and water stress and soil amendments with such beneficial strain could provide stability to other microbes under stressed conditions. In another study of similar nature negligible effect of carbon dioxide (757 ppm) was observed on fungal community structure and ITS gene copy number while there was increase in diversity of archaea and decrease in bacterial diversity. Bacterial communities are strongly determined by carbon dioxide concentration as compared to fungal communities, a striking dissimilarity was noted in this study. Fungal groups are slow growers and secondly labile carbon available was not enough to induce a shift that could result in the absence of response (Lee et al., 2015).

Major source of nitrous oxide emission in agriculture soils is released though incomplete denitrification. A study utilizing AMF Rhizophagus irregularis to manage nitrous oxide production from Zea mays field demonstrates the importance of utilization of fungi in reducing the production of this potent green house gas (Storer et al., 2018). Such studies suggest a future for green house gas reduction and climate change mitigation employing fungi.

5.3. Rainfall and drought: Fungal taxonomic shift was observed in a long term field monitoring on Salix viminalis (willow). There was around $30 \%$ decline in the Basidiomycota and significant decline in Zygomycota after a post extreme rainfall whereas least deviation in the Ascomycota group was observed. Truncatella angustata, Plectopharella, Pilidium, Motierellaceae, Sporomiaceae, Cryptococcus and lichenized fungi like Venturiaceae and Verrucaria andesiatica increased in abundance post rainfall (Barnes et al., 2018). On the contrary in a study conducted for over a period of 17 years in grass land ecosystem, a remarkable difference was observed in summer drought condition on fungal assemblages wherein 66 of the 208 fungal 
taxa were entirely absent. Shifts in fungi is related to leaf dry matter content, whereas changes in soil bacteria are related more to differences in plant $\mathrm{C}: \mathrm{N}$ ratios (Sayer et al., 2017). In a comparative analysis of fungal and bacterial communities in drought condition fungal evenness and richness increased during drought. Bacterial communities were not resilient as they were previously thought to be. Drought indicators belonged to the phyla Ascomycota and Glomeromycota and sensitive indicators included phylum Zygomycota. Moreover, unlike bacteria, fungal tolerant indicators were found to be more connected (de Vries et al., 2018). Wet land response to climate change suggest that fungi are less sensitive than other microbial groups to external factors such as carbon dioxide and nitrogen (Lee et al., 2015). Such studies are important in framing patterns of different ecosystems.

4.4. Wildfires: Climate is changing at a fast pace and with frequent wild fires of especially Colorado a new term has emerged, 'fire tsunami' (https:/grist.org/article/weveentered-the-era-of-fire-tsunamis/). Wildfires are a direct consequence of climate change and have become a serious threat to forest ecosystem as it impairs the recovery of endangered trees post wildfire. There are certain regions in western US which are assumed to surpass 'critical climate threshold,' a term that is used to indicate regions that may not return to normal after wildfires. Ponderosa pine and Douglas fir, important trees for timber industry are endangered and less likely to regenerate themselves after wildfire thus are on the verge of being locally extinct (Davis et al., 2018). Fungi are an integral component of forest ecosystem and certain ECM are specific and grow in close association with only specific plant species, eg. Russula delica is more abundant on Betula papyrifera roots but is barely detected on Quercus rubra roots (Mucha et al., 2018). A very limited studies suggest that these fungi could also become locally extinct in the face of climate change. Interestingly, Murata and colleagues (2017) in a study conducted on 104 Pine forests observed that Rhizopogon sp. associated with endangered Pinus amamiana forests was present at all sites that suggests a possible role of the species in seedling establishment of this tree and efforts could be made to conserve such endangered plants from facing extinction.

\section{ADAPTATIONS IN FUNGI}

There are now several reports that indicate that fungi adapt themselves to the changing environment. One such drug resistant fungus known as Candida auris has been reported and scientists have termed it as 'superfungus'. Scientists strongly believe that its ability to spread across the world is on account of its growth at warmer temperature $\left(37^{\circ} \mathrm{C}\right)$ (Casadevall et al., 2019). Sometimes adaptation leads to the advantage of reproductive success in mushroom assemblages that becomes significantly darker in areas with cold climate, an example of the adaptive selection residing in thermal environment. (Krah et al., 2019). In a study by Andrew et al. (2016), authors observed the adaptation involving sporocarp production and spore volumes where smaller spore volumes were associated with warmer temperature and greater spore volumes were found to be associated with increased humidity. Species having veined hymenial layer like Cantharellus,
Craterellus and Pseudocraterellus were less abundant with increased humidity. It has also been noticed that increase in temperature can also affect the morphology of fungi through hyphal branching, radial extension rate and hyphal coverage (A'Bear et al., 2012). Minor change in mean annual temperature by $0.2^{\circ} \mathrm{C}$ has an effect on timing of spore producing structure which can delay it by 1 day. Climate change can also have adverse effect on fungal reproductive timing (Andrew et al., 2016). The increase in fungal diversity in warmer regions has its negative implication on human health as more heat tolerant fungi could emerge or they adapt to become thermally resistant (Table 1).

Table 1: Various adaptation in fungi due to climate change

\begin{tabular}{|c|c|c|c|}
\hline $\begin{array}{l}\text { S. } \\
\text { No. }\end{array}$ & Adaptation & Importance & Reference \\
\hline 1 & Thick walled spores & $\begin{array}{l}\text { Thickening in walls of spores can help } \\
\text { them withstand temperature and water } \\
\text { stressed conditions }\end{array}$ & Koide et al. (2014) \\
\hline 2. & Melanisation & $\begin{array}{l}\text { Melanin serves dual purpose. Resist fungi } \\
\text { from desiccation and may provide } \\
\text { mechanical strength in case of drought to } \\
\text { transport water from long distance } \\
\text { through hyphee }\end{array}$ & $\begin{array}{l}\text { Fernandez and Koide } \\
\text { (2013) }\end{array}$ \\
\hline 3. & Rhizomorphs & $\begin{array}{l}\text { Specialized fungal structures to transport } \\
\text { water and nutrients and to withstand harsh } \\
\text { conditions of the environment }\end{array}$ & Yaffeto et al. (2009) \\
\hline 4. & Jelly fungi & $\begin{array}{l}\text { These fungi can withstand repeated heat } \\
\text { and cold environment and can survive } \\
\text { even under scarcity of water }\end{array}$ & $\begin{array}{l}\text { Webster and Weber } \\
\text { (2007) }\end{array}$ \\
\hline 5. & $\begin{array}{l}\text { Dormant spores/ } \\
\text { sclerotia }\end{array}$ & $\begin{array}{l}\text { Sclerotia are dormant structures survive } \\
\text { for several years in soil in dormant phase } \\
\text { and can face harsh conditions like high } \\
\text { temperatures and wildfire. Fungi may } \\
\text { reappear under suitable conditions. }\end{array}$ & Koide et al. (2014) \\
\hline
\end{tabular}

In a first long term study Romero Olivares et al. (2015) tested adaptation in strain of Neurospora at $16{ }^{\circ} \mathrm{C}$ and $28{ }^{\circ} \mathrm{C}$. The mycelial growth rate and biomass was not altered whereas adapted strains produced more energetically expensive spores per unit biomass and higher mass specific respiration. Contrary to general expectations their findings did not support the idea that global warming will lead to increase in carbon use efficiency.

Another interesting example of how fungi respond to huge selection pressure exerted by climate change is observed in Ophiocordyceps kimflemingiae (zoombie ant fungus) and its adaptation to local condition. This fungus infects carpenter ants without affecting their brains and while deriving nutrition from ants they also control the biting behaviour so that the tropical zombie ants always bite on leaves and temperate zombie ants always bites on twigs and bark (de Bekker et al., 2015).

Lichens are highly vulnerable to climate change and there is sharp decline in their population in arctic / alpine regions in much of area now covered with vascular plants. They show diverse adaptive features in the climate change scenario. In drought condition they alter their morphology by increasing mass per area to retain more water during stressful condition. They also have the capability of switching photosynthetic partners or can also migrate (Larsson et al., 2012).

\section{CONCLUSION}

Fungi are cosmopolitan in distribution and are efficient drivers of soil carbon feedback cycles than other microbial 
species. They contribute towards a major portion of green house gases into the atmosphere. The situation is more alarming because "it implies we've added a lot of soil carbon back to the atmosphere as carbon dioxide, and our current models of the climate system do not represent this carbon dioxide emission pathway through fungi" (Averill et al., 2018).

Laboratory experiments and data on mesocosm, in situ field experimentation and knowledge of fungal diversity and its evolutionary component required to understand any in situ change. Climate change demands long term study to observe effects that are important especially in nutrient poor quality soils and slow growing vegetation since many fungal species are slow growing therefore demand long term monitoring to understand the impacts of global climate change on fungal communities. Prominent shifts in community structure are reported in various studies. This knowledge could be utilized to introduce a new fungal genera or replenishing the existing fungal community like with AMF to successfully reduce green house gas emission or employing soil fungus Trichoderma reesei in biofuel production to lessen down the effect of climate change.

Key factors like temperature, rainfall, wildfires expedite the process of climate change due to which biodiversity is fast declining. However, due to lack of uncharacterized diversity of microbes, a connection between fungi and climate change is still unknown. As a result the native fungal species of any region might go locally extinct or might facilitate the establishment of invasive species that may pose competition or extinction of certain species across region sometimes which might therefore go undocumented. Above all, such studies suggest that anthropogenic signal for climate change is likely to increase in the near future and one might expect the fungal communities to eventually experience more substantial transformation in their community structure. Million of hectares of pristine tropical rain forest for paper and palm industry are destroyed in the past few years along with their ECM component and loss, if any, in such destruction remains undocumented. It alarms humankind to check such usages before consumption of plant derived products that confers an indirect effect on nature or climate. In culmination every action that mankind now makes requires its climatic ramifications to avoid major disturbances in nature.

\section{REFERENCES}

A'Bear, A. D., Boddy, L. and Hefin Jones, T. 2012. Impacts of elevated temperature on the growth and functioning of decomposer fungi are influenced by grazing collembola. Global Change Biol. 18 (6): 1823-1832.

Allison, S.D. and Treseder, K.K. 2011. Climate change feedbacks to microbial decomposition in boreal soils. Fungal Ecol. 4 (6): 362-374.

Amend, A., Burgaud, G., Cunliffe, M., Edgcomb, V. P., Ettinger, C. L., Gutiérrez, M. H. et al. 2019. Fungi in the marine environment: open questions and unsolved problems. MBio. 10 (2): e01189-18.
Andrew, C., Heegaard, E., Halvorsen, R., Martinez-Peña, F. Egli, S., Kirk, P.M., Basselur, C., Büntgen, U., Aldea, J., Klaus Høiland, K., Boddy, L.and Kauserud H. 2016. Climate impacts on fungal community and trait dynamics. Fungal Ecol. 22: 1725.

Asemaninejad, A., Thorn, R. G., Branfireun, B. A. and Lindo, Z. 2018. Climate change favours specific fungal communities in boreal peatlands. Soil Biol Biochem. 120: $28-36$.

Averill, C., Dietze, M.C. and Bhatnagar, J.M. 2018. Continental-scale nitrogen population in shifting forest mycorrhizal association and soil carbon stocks. Global Change Biol. 24 (10): 4544-4553.

Bailey, V.L., Bond-Lamberty, B., DeAngelis, K., Grandy, A., Hawkes, C.V., Heckman, H.K. and Lajtha, K. et al. 2018. Soil carbon cycling proxies: understanding their critical role in predicting climate change feedbacks. Global Change Biol. 24: 895-905. PNNL-SA-128644. doi:10.1111/gcb.13926

Bajpai, A., Rawat, S. and Johri, B.N. 2019. Microbial Diversity in Ecosystem Sustainability and Biotechnological Applications (Eds.: Satyanarayana, T. et al.). Springer Nature Singapore Pte Ltd. Https://doi.org/10.1007/978-981-13-83151 . 4 .

Barnes, C.J., van der Gast, C.J., McNamara, N.P., Rowe, R. and Bending, G.D. 2018. Extreme rainfall affects assembly of the root-associated fungal community. New Phytol. 220 (4): 1172-1184.

Bar-On, Y.M., Phillips, R. and Milo, R. 2018. The biomass distribution on Earth. Proc. Natl. Acad. Sci. 201711842.

Bastin, J. F., Finegold, Y., Garcia, C., Mollicone, D., Rezende, M., Routh, D. et al. 2019. The global tree restoration potential. Sci. 365 (6448): 76-79.

Behrenfeld, M. J., Hu, Y., O'Malley, R. T., Boss, E. S., Hostetler, C. A., Siegel, D. A. et al. 2017. Annual boombust cycles of polar phytoplankton biomass revealed by space-based lidar. Nat. Geosci. 10 (2): 118.

Behrenfeld, M.J. 2014. Climate- mediated dance of the plankton. Nat. Clim. Change 4(10): 880-887.

Berger, J.J. 2019. Can soil microbes slow climate change? Scientific American.

Blackwell, M. 2011. The fungi: 1, 2, 3 ... 5.1 million species? Am. J. Bot. 98: 426-438.

Carvalhais, N., Forkel, M., Khomik, M., Bellarby, J., Jung, M., Migliavacca, M., et al. 2014. Global covariation of carbon turnover times with climate in terrestrial ecosystems. Nat.514(7521): 213.

Casadevall, A., Kontoyiannis, D.P. and Robert, V. 2019. On the emergence of Candida auris: Climate Change, 
Azoles, Swamps, and Birds. Mbio. 10 (4)DOI:10. 1128/mBio.01397-19

Clemmensen, K.E., et al. 2013. Roots and associated fungi drive long-term carbon sequestration in boreal forest. Sci. 29: 1615-1618.

Comeau, A.M., Vincent, W.F., Bernier, L. and Lovejoy, C. 2016. Novel chytrid lineages dominate fungal sequences in diverse marine and freshwater habitats. Sci.Rep. 6: 30120.

Comeau, S., Cornwall, C.E., DeCarlo, T.M., Doo, S.S., Carpenter, R. C. and McCulloch, M.T. 2019. Resistance to ocean acidification in coral reef taxa is not gained by acclimatization. Nat. Clim. Change. 9 (6): 477.

Cunliffe, M., Hollingsworth, A., Bain, C., Sharma, V. and Taylor, J.D. 2017. Algal polysaccharide utilisation by saprotrophic planktonic marine fungi. Fungal Ecol. 30:135-138. Https://doi.org/10.1016/ j.funeco.2017.08.009.

Davis, K.T., Higuera, P.E. and Sala, A. 2018. Anticipating fire-mediated impacts of climate change using a demographic framework. Func. Ecol. 32 (7): 17291745 .

de Bekker, C., Ohm, R.A., Loreto, R.G., Sebastian, A., Albert, I., Merrow, M. et al. 2015. Gene expression during zombie ant biting behavior reflects the complexity underlying fungal parasitic behavioral manipulation. BMC Genomics. 16 (1): 620. Doi:10. 1186/s12864-015-1812-x.

de Vries, F. T., Griffiths, R. I., Bailey, M., Craig, H., Girlanda, M., Gweon, H. S. et al. 2018. Soil bacterial networks are less stable under drought than fungal networks. Nat. commun. 9 (1): 3033.

Egidi, E., Delgado-Baquerizo, M., Plett, J. M., Wang, J., Eldridge, D. J., Bardgett, R. D. et al. 2019. A few Ascomycota taxa dominate soil fungal communities worldwide. Nat. commun. 10 (1): 2369.

Enochs, I.C. et al. 2015. Shift from coral to macroalgae dominance on a volcanically acidified reef. Nat. Clim. Change. 5: 1083-1088.

EPA, 2016 , Future Of Climate Change https://www.epa.gov/climate--change--science/ future--climate--change, (December 10, 2016).

Fernandez, C.W. and Koide, R.T. 2013. The function of melanin in the ectomycorrhizal fungus Cenococcum geophilum under water stress. Fungal Ecol. 6: 479486.

Flemming, H. C. and Wuertz, S. 2019. Bacteria and archaea on Earth and their abundance in biofilms. Nat. Rev. Microbiol. 17: 247-260.

Fretwell, P. T. and Trathan, P. N. 2019. Emperors on thin ice: three years of breeding failure at Halley Bay. Antarctic Sci. 31(3): 133-138.
Gloor, E. 2019. The fate of Amazonia. Nat. Clim. Change. 9 (5): 355 .

Hawksworth, D.L. 1991. The fungal dimension of biodiversity: Magnitude, significance, and conservation. Mycol. Res. 95: 641-655.

Hawksworth, D.L. 2001. The magnitude of fungal diversity: the 1.5 million species estimate revisited. Mycol. Res. 105: 1422-1432.

Hawksworth, D.L. and Lücking, R. 2017. Fungal diversity revisited: 2.2 to 3.8 million species. In: The Fungal Kingdom (Eds.: Heitman, J., Howlett, B.J., Crous, P.W., Stukenbrock, E.H., James, T.Y. and Gow, N.A.R.). Washington, DC: Am. Soc. Microbiol. pp 79-95.

Holding, J.M. et al. 2015. Temperature dependence of $\mathrm{CO}_{2}-$ enhanced primary production in the European Arctic Ocean. Nat. Clim. Change. 5: 1079-1082.

Hurd, C. L., Lenton, A., Tilbrook, B. and Boyd, P. W. 2018.Current understanding and challenges for oceans in a higher- $\mathrm{CO} 2$ world. Nat. Clim. Change. 8: 686-694

Hutchins, D.A. and Fu, F.X. 2017. Microorganisms and ocean global change. Nat. Microbiol. 2: 17508.

IPCC, 2013: Climate Change 2013: The Physical Science Basis. Contribution of Working Group I to Fifth Assessment Report of the Intergovernmental Panel on Climate Change (Eds.: Stocker, T.F., Qin, D., Plattner, G.-K., Tignor, M., Allen, S.K., Boschung, J., Nauels, A., Xia, Y., Bex, V. and Midgley, P.M.). Cambridge University Press, Cambridge, United Kingdom and New York, NY, USA, 1535 pp.

Jones, E.B.G. 2011. Fifty years of marine mycology. Fungal Diversity. 50: 73-112. doi:10.1007/s13225-0110119-8.

Khan, S., Nadir, S., Shah, Z.U., Shah, A.A., Karunarathna, S.C., Xu, J. et al. 2017. Biodegradation of polyester polyurethane by Aspergillus tubingensis. Environ. Pollution 225: 469-480.

Kirchman, D. L., Morán, X. A. and Ducklow, H. 2009. Microbial growth in the polar oceans - role of temperature and potential impact of climate change. Nat. Rev. Microbiol. 7: 451-459.

Kohler, J., Caravaca, F., del Mar Alguacil, M. and Roldán, A. 2009. Elevated CARBON DIOXIDE increases the effect of an arbuscular mycorrhizal fungus and a plant-growth-promoting rhizobacterium on structural stability of a semiarid agricultural soil under drought conditions. Soil Biol. Biochem. 41(8): 1710-1716.

Kohlmeyer, J., and Kohlmeyer, E. 1979. Marine Mycology: The higher Fungi. Academic Press, New York, NY.

Koide, R. T., Fernandez. C. and Malcolm, G. 2014. Determining place and process: Functional traits of 
ectomycorrhizal fungi that affect both community structure and ecosystem function. New Phytol. 201: 433-439.

Krah, F. S., Büntgen, U., Schaefer, H., Müller, J., Andrew, C., Boddy, L. et al. 2019. European mushroom assemblages are darker in cold climates. Nat. commun. 10 (1): 2890.

Landenmark, H.K.E., Forgan, D.H. and Cockell, C.S. 2015. An estimate of the total DNA in the biosphere. PLoS Biol. 13:e1002168.

Larsson, P., Solhaug, K. A. and Gauslaa, Y. 2012. Seasonal partitioning of growth into biomass and area expansion in a cephalolichen and a cyanolichen of the old forest genus Lobaria. New Phytol. 194 (4): 991-1000.

Lee, J. R., Raymond, B., Bracegirdle, T. J., Chades, I., Fuller, R. A., Shaw, J. D. and Terauds, A. 2017. Climate change drives expansion of Antarctic ice-free habitat. Nat. 547 (7661): 49.

Lee, S.H., Kim, S.Y., Ding, W. and Kang, H. 2015. Impact of elevated $\mathrm{CO}_{2}$ and $\mathrm{N}$ addition on bacteria, fungi, and archaea in a marsh ecosystem with various types of plants. Appl. Microbial. Biotechnol. 99 (12): 5295 5305.

Lenzen, M., Sun, Y. Y., Faturay, F., Ting, Y. P., Geschke, A., and Malik, A. 2018. The carbon footprint of global tourism. Nat. Clim. Change. 8(6): 522.

Lewis, S.L., Wheeler, C.E., Mitchard, E.T. and Koch, A. 2019. Restoring natural forests is the best way to remove atmospheric carbon. Nat. 568: 25-28.

Liggenstoffer, A.S., Youssef, N.H., Couger, M.B. and Elshahed, M.S. 2010. Phylogenetic diversity and community structure of anaerobic gut fungi (Phylum Neocallimastigomycota) in ruminant and non-ruminant herbivores. ISME J. 4 (10): 1225.

Madden, R.A. and Ramanathan, V. 1980. Detecting climate change due to increasing carbon dioxide. Sci. 209 (4458): 763-768.

Mei, L., Yang, X., Cao, H., Zhang, T. and Guo, J. 2019. Arbuscular mycorrhizal fungi alter plant and soil C: $\mathrm{N}$ : P stoichiometries under warming and nitrogen input in a semiarid meadow of China. Int. J. Environ. Res. Public Health. 16(3): 397.

Melillo, J.M., Frey, S.D., De Angelis, K.M., Werner, W., Bernard, M.J., Bowles, F.P., Pold, G., Knorr, M.A. and Grandy, A.S. 2017. Long-term Pattern and Magnitude of Soil Carbon Feedback to the Climate System in a Warming World. Sci. 358: 101-105. DOI: $10.1126 /$ science.aan 2874

Morgado, L.N., Semenova, T.A., Welker, J.M., Walker, M.D., Smets, E. and Geml, J. 2015. Summer temperature increase has distinct effects on the ectomycorrhizal fungal communities of moist tussock and dry tundra in Arctic Alaska. Global change Biol. 21 (2): 959-
972.

Mucha, J., Peay, K. G., Smith, D. P., Reich, P. B., Stefański, A., and Hobbie, S.E. 2018. Effect of simulated climate warming on the ectomycorrhizal fungal community of boreal and temperate host species growing near their shared ecotonal range limits. Microbial Ecol. 75 (2): 348-363.

Murata, M., Kanetani, S. and Nara, K. 2017. Ectomycorrhizal fungal communities in endangered Pinus amamiana forests. PloSone 12 (12): e0189957.

NASA, 2016, The Consequence of Climate Change, California Institute of Technology http://climate. nasa.gov/effects/(December 9, 2016).

Newsham, K. K., Hopkins, D. W., Carvalhais, L. C., Fretwell, P. T., Rushton, S. P., O'Donnell, A. G. and Dennis, P. G. 2016. Relationship between soil fungal diversity and temperature in the maritime Antarctic. Nat. Clim. Change. 6(2):182.

O'Brien, B.L., Parrent, J.L., Jackson, J.A., Moncalvo, J.M. and Vilgalys, R. 2005. Fungal community analysis by large-scale sequencing of environmental samples. Appl. Environ. Microbiol. 71: 5544-5550.

Paço, A., Duarte, K., da Costa, J. P., Santos, P. S., Pereira, R., Pereira, M. E. et al. 2017. Biodegradation of polyethylene microplastics by the marine fungus Zalerion maritimum. Sci. Total Environ. 586: 10-15.

Pang, K.L., Overy, D.P., Jones, E.G., da Luz Calado, M., Burgaud, G., Walker, A. K. et al. 2016. 'Marine fungi'and 'marine-derived fungi' in natural product chemistry research: toward a new consensual definition. Fungal Biol. Rev. 30 (4): 163-175.

Raftery, A.E., Zimmer, A., Frierson, D.M., Startz, R. and Liu, P. 2017. Less than $2 \mathrm{C}$ warming by 2100 unlikely. Nat. Clim. Change 7 (9): 637.

Romero-Olivares, A. L., Taylor, J. W. and Treseder, K. K. 2015. Neurospora discreta as a model to assess adaptation of soil fungi to warming. BMC Evol. Biol. 15(1): 198 .

Sayer, E. J., Oliver, A. E., Fridley, J. D., Askew, A. P., Mills, R. T. and Grime, J. P. 2017. Links between soil microbial communities and plant traits in a species rich grassland under long term climate change. Ecol. Evol. 7 (3): 855-862.

Scheele, B. C., Pasmans, F., Skerratt, L. F., Berger, L., Martel, A., Beukema, W. et al. 2019. Amphibian fungal panzootic causes catastrophic and ongoing loss of biodiversity. Sci. 363 (6434): 1459-1463.

Schoch, C. L., Crous, P. W., Groenewald, J. Z., Boehm, E. W. A., Burgess, T. I., De Gruyter, J. et al. 2009. A classwide phylogenetic assessment of Dothideomycetes. Stud. Mycol. 64:1-15.

Sinsabaugh, R.L., Manzoni, S., Moorhead, D.L. and Richter, A. 2013. Carbon use efficiency of microbial 
communities: stoichiometry, methodology and modelling. Ecol. Lett. 16: 930-939.

Smith, M.R. and Myers, S.S. 2018. Impact of anthropogenic $\mathrm{CO}_{2}$ emissions on global human nutrition. Nat. Clim. Change. 8(9): 834.

Staddon, P.L., Heinemeyer, A. and Fitter, A.H. 2002. Mycorrhizas and global environmental change: research at different scales. Plant Soil. 244 (1-2): 253-261.

Steidinger, B. S., Crowther, T. W., Liang, J., Van Nuland, M. E., Werner, G. D. A., Reich, P. B. et al. 2019. Climatic controls of decomposition drive the global biogeography of forest-tree symbioses. Nat. $\mathbf{5 6 9}$ (7756): 404

Storer, K., Coggan, A., Ineson, P. and Hodge, A. 2018. Arbuscular mycorrhizal fungi reduce nitrous oxide emissions from $\mathrm{N}_{2} \mathrm{O}$ hotspots. New Phytol. 220 (4): 1285-1295.

Sunagawa, S. et al. 2015. Structure and function of the global ocean microbiome. Sci. 348: 1261359.

Tedersoo, L., Bahram, M., Põlme, S., Kõljalg, U., Yorou, N. S., Wijesundera, R. et al. 2014. Global diversity and geography of soil fungi. Sci.346 (6213): 1256688.

Terrer, C., Vicca, S., Hungate, B.A., Phillips, R.P. and Prentice, I.C. 2016. Mycorrhizal association as a primary control of the carbon dioxide fertilization effect. Sci. 353 (6294): 72-74.

Torda, G., Donelson, J. M., Aranda, M., Barshis, D. J., Bay, L., Berumen, M. L. et al. 2017. Rapid adaptive responses to climate change in corals. Nat. Clim. Change. 7 (9): 627.

Treseder, K.K., Marusenko, Y., Romero-Olivares, A.L. and Maltz, M.R. 2016. Experimental warming alters potential function of the fungal community in boreal forest. Global Change Biol. 22 (10): 3395-3404.

Weber, C.F., Zak, D.R., Hungate, B.A., Jackson, R.B., Vilgalys, R., Evans, R.D. et al. 2011. Responses of soil cellulolytic fungal communities to elevated atmospheric carbon dioxide are complex and variable across five ecosystems. Environ. Microbiol. 13 (10): 2778-2793.

Webster, J. and Weber, R. 2007. Introduction to Fungi. $3^{\text {rd }}$ ed. Cambridge University Press, Cambridge, UK

Woinarski, J. and Burbidge, A.A. 2016. Melomys rubicola. The IUCN Red List of Threatened Species 2016:e.T13132A97448475. Http://dx.doi.org/ 10.2305/IUCN.UK.2016-2.RLTS.T13132A97 448475.en.

Woodcock, P., Cottrell, J.E., Buggs, R.J. and Quine, C.P. 2017. Mitigating pest and pathogen impacts using resistant trees: a framework and overview to inform development and deployment in Europe and North America. Forestry: An Int. J. Forest Res. 91 (1): 116.

Yafetto, L., Davis, D.J. and Money, N.P. 2009. Biomechanics of invasive growth by Armillaria rhizomorphs. Fungal Genet. Biol. 46: 688-694. 